\title{
Predictive and Prognostic Impact of Tumor-Infiltrating Lymphocytes (CD8+) In Breast Cancer Treated With Neoadjuvant Chemotherapy \\ Zeinab Mohammed Abdel-Hafeez Elsayed ${ }^{1}$, Mohammad Sabry Elkady ${ }^{1}$, Waleed Abd Elmmonem Biomy ${ }^{1}$, Mai Mohamed Ali Ezz El Din ${ }^{1}$, Manal Mohamed El Mahdy ${ }^{2}$, Tag Ibrahim Omran ${ }^{3}$, Radwa Mohamed Sabra ${ }^{3}$ \\ Department of ${ }^{1}$ Clinical Oncology and Nuclear Medicine and Department of ${ }^{2}$ Clinical Pathology Faculty of Medicine, Ain Shams University, ${ }^{3}$ Maadi Armed Forces Medical Compound \\ Corresponding author: Radwa Mohamed Sabra, E-mail: Radwahamed7@ gmail.com, Telephone: (+2) 01003935960
}

\begin{abstract}
Background and Objectives: the use of neoadjuvant chemotherapy (NAC) in breast cancer induces a pCR in only $30-35 \%$ of patients. We can't depend only on clinical and pathological factors to distinguish the patients who have no chance of a pCR or not. Moreover, the NAC scenario is the perfect setting to study possible changes in TIL levels. Tumor-infiltrating lymphocytes (TIL) (CD) 8+ are essential components of tumorspecific cellular adaptive immunity. However, only few studies have addressed the significance of (CD8+) TIL in patients with breast cancer. Patients and Methods: we assessed the stromal and intratumral TIL, CD+8 in pretreatment core biopsy by immuohistochemistry (IHC) in 45 patients with breast cancer received neoadjuvant anthracyclin and docetaxel chemotherapy. CD8 classified into high or low according to the inter quartile range. Tumors with $\geq 50 \%$ intratumoral or stromal lymphocytes were designated lymphocyte predominant breast cancer (LPBC). Results: we found statistically significant correlation with high CD8 and DFS and smaller tumor residual $(95 \% \mathrm{CI}, 18.6-22.9 ; \mathrm{P}=0.01)$ and $(\mathrm{p}=0.003)$ respectively. But there was no significant difference regarding pCR or OS between high and low groups. Conclusion: this study confirmed that the CD8 TIL is an important prognostic and predictive factor in breast cancer.
\end{abstract}

Keywords: Breast cancer, CD8, Tumor infiltrating lymphocytes.

\section{INTRODUCTION}

Breast cancer is the most common invasive malignancy and the second most common cause of death from cancer in women ${ }^{(1)}$. Over 1.5 million women $(25 \%$ of all women with cancer) are diagnosed with breast cancer every year throughout the world. In America, it is estimated that $30 \%$ of all new cancer cases among women are breast cancer in $2017^{(2)}$. In Egypt Like other countries the age specific incidence rate shows progressive increase after the age of 30 years, to reach a sharp peak of $177.4 / 100000$ at the age group of 60-64 years $^{(3)}$. Historically breast cancer was not thought to be immunologically active, particularly when compared to other tumors like melanoma. But recent data has confirmed that tumor infiltrating lymphocytes (TILs) present in breast cancer prior to treatment can predict response to therapy and improved prognosis ${ }^{(4)}$. During the early stages of this process, immune-surveillance-related lymphocytes (CD8+ T cells, CD4+ type-1 T-helper (Th-1) cells, and natural killer (NK) cells) are able to recognize and eliminate malignant cells $^{(5)}$. Seventy-five percent of TILs are found to be T cells. Among these, CD8 cytotoxic T lymphocytes (CTLs) cells represent the class of lymphocytes that correlate better with overall favorable clinical outcome ${ }^{(6)}$. It exhibits cytotoxic activity towards tumor cells expressing tumor associated antigens (TAAs) ${ }^{(7)}$. This adaptive immune response is mediated via major histocompatibility complex (MHC), where CD8+ T cells induce tumor cell death directly upon recognition of tumor protein presented in association with MHC class I molecules on tumor cells ${ }^{(8)}$.

\section{PATIENTS AND METHODS}

This is a prospective, single arm, clinical trial which carried on 45 female patients with locally advanced breast cancer at both Clinical Oncology and Nuclear Medicine department Ain Shams university hospital and Maadi Armed Forces Medical Compound. All patients received Preoperative chemotherapy including both taxanes and anthracyclines. Flurouracil (500 $\mathrm{mg} / \mathrm{m} 2 / 21$ days), ebirubicin (100 $\mathrm{mg} / \mathrm{m} 2 / 21$ days) and cyclophosphamide (500 mg/m2/21days), for three or four cycles, followed by docetaxel (75-100 $\mathrm{mg} / \mathrm{m} 2 / 21$ days) for three or four cycles followed by radical surgery according to response, radiotherapy and hormonal treatment is HR positive cases. The study was approved by the Ethics Board of Ain Shams University and an informed written consent was taken from each participant in the study. The paraffin blocks from all 45 patients were retrieved from the histopathology units at both centers. Then, $2-\mu \mathrm{m}$ 
thick sections were cut from the pre-chemotherapy biopsies. The sections obtained were processed and stained with $H \& E$ in order to identify the areas with dense lymphocytic infiltration. Furthermore, unstained sections were subsequently obtained and stained using an IHC method for CD8+ T cells. Assessment of intratumoral and stromal TILs was done based on Immuno-Oncology Biomarker Working Group guidelines.TIL scores were defined as the percentage of tumor area that was occupied by inflammatory (CD8) cells. TILs were scored as continuous variables with positivity cutoff set at 1\%. Intratumoral and stromal TIL (CD8) lymphocytes expression levels were classified as either high and low based on values $\geq$ or $<$ the inter quartile range of each, respectively. Tumors with $\geq$ $50 \%$ intratumoral or stromal lymphocytes were designated lymphocyte predominant breast cancer (LPBC). After taking the approval of research ethics committee (EC) of Faculty of medicine, Ain Shams University to perform this study, written informed consent was obtained from all participants. Statistical Analysis: SPSS package (version 22.0) is used for data analysis. The association between clinical and pathologic parameters was tested with $\chi^{2}$ test. Numerical data were expressed as mean and standard deviation or median and range as appropriate. Qualitative data were expressed as frequency and percentage. Chisquare test (Fisher's exact test) was used to examine the relation between qualitative variables. Disease free survival and overall survival will be estimated using Kaplan-Miere method.

\section{RESULTS}

A total of 45 patients with locally advanced breast cancer were enrolled into the present study. The demographic and clinicopathological data of patients are presented in Table I. Characteristically, Patient age ranged between (33-66) with median age 53 years. Most of patients were older than 35 years old (93\%). Premenopausal females 21 patients $(46 \%)$ and postmenopausal 24 (53\%).
Table (1): Tumor characteristics

\begin{tabular}{|c|c|c|}
\hline Characteristic & Number & Percentage\% \\
\hline $\begin{array}{l}\text { Pathological types } \\
\text { Invasive duct carcinoma } \\
\text { Medullary carcinoma }\end{array}$ & $\begin{array}{c}44 \\
1\end{array}$ & $\begin{array}{c}97.0 \\
3.0\end{array}$ \\
\hline $\begin{array}{l}\text { Grade } \\
\text { Grade I } \\
\text { Grade II } \\
\text { Grade III }\end{array}$ & $\begin{array}{c}0 \\
38 \\
7\end{array}$ & $\begin{array}{c}0 \\
84.4 \\
15.5\end{array}$ \\
\hline $\begin{array}{l}\text { Lymph node positivity } \\
\text { Positive } \\
\text { Negative } \\
\end{array}$ & $\begin{array}{c}39 \\
6\end{array}$ & $\begin{array}{l}86.6 \\
13.3\end{array}$ \\
\hline $\begin{array}{l}\text { Tumor size } \\
\text { T1 } \\
\text { T2 } \\
\text { T3 } \\
\text { T4 }\end{array}$ & $\begin{array}{c}0 \\
26 \\
7 \\
12\end{array}$ & $\begin{array}{c}0 \\
57.7 \\
15.5 \\
26.6\end{array}$ \\
\hline $\begin{array}{l}\text { Tumor number } \\
\text { Single } \\
\text { Multifocal } \\
\end{array}$ & $\begin{array}{l}32 \\
13 \\
\end{array}$ & $\begin{array}{l}71.0 \\
28.8 \\
\end{array}$ \\
\hline $\begin{array}{l}\text { Estrogen receptors } \\
\text { Positive } \\
\text { Negative }\end{array}$ & $\begin{array}{l}27 \\
18\end{array}$ & $\begin{array}{l}60.0 \\
40.0\end{array}$ \\
\hline $\begin{array}{l}\text { Progesterone receptors } \\
\text { Positive } \\
\text { Negative } \\
\end{array}$ & $\begin{array}{l}23 \\
22 \\
\end{array}$ & $\begin{array}{l}51.1 \\
48.8\end{array}$ \\
\hline $\begin{array}{l}\text { HER } 2 \text { receptors } \\
\text { Positive } \\
\text { Negative } \\
\end{array}$ & $\begin{array}{l}20 \\
25\end{array}$ & $\begin{array}{l}55.5 \\
44.5\end{array}$ \\
\hline $\begin{array}{l}\text { KI67 } \\
>20 \% \\
<20 \%\end{array}$ & $\begin{array}{l}10 \\
35\end{array}$ & $\begin{array}{l}22.2 \\
77.7\end{array}$ \\
\hline $\begin{array}{l}\text { Molecular subtypes } \\
\text { Luminal A } \\
\text { Luminal B } \\
\text { Her 2 }\end{array}$ & $\begin{array}{c}4 \\
23 \\
10\end{array}$ & $\begin{array}{c}8.8 \\
51.1 \\
22.2\end{array}$ \\
\hline Triple negative & 8 & 17.7 \\
\hline
\end{tabular}

In our study, 44 (97.7\%) patients received neoadjuvant FEC and docetaxel chemotherapy, only $1(2.2 \%)$ patient achieved pCR after 4 cycles only of FEC so received docetaxel as adjuvant, only only $7(35 \%)$ of 20 HER 2 positive patients received neoadjuvant trastuzumab, $16(80 \%)$ received it as adjuvant and $10(50 \%)$ patients completed 1 year trastuzumab. We had $44(97.7 \%)$ CD8 positive and only $1(0.2 \%) \mathrm{CD} 8$ negative. We had only 4 patients with LPBC $(8.8 \%)$ and it matches with the international data as LPBC represents only $10 \%$ of breast cancer cases. To classify our cohort into high and low TIL we used the inter quartile range (IQR), patients equal to or higher than the IQR considered high TIL infiltration. High CD8 significantly improved the 
DFS (95\% CI, 18.6-22.9; P= 0.01). Table (II): high CD8 associated with smaller tumor residual $(\boldsymbol{p}=\mathbf{0 . 0 0 3})$. But there was no significant difference regarding $\mathrm{pCR}$ or $\mathrm{OS}$ between high and low groups. Regarding the association between CD8 and different clinic-pathological factors only the molecular subtype had a significant difference with CD8, Her2 subtype had higher CD8 expression $(P=0.018)$.

Table (2): Tumor residual in correlation to CD8

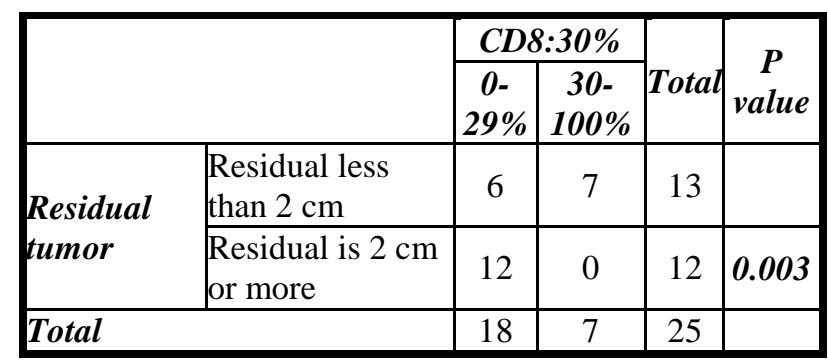

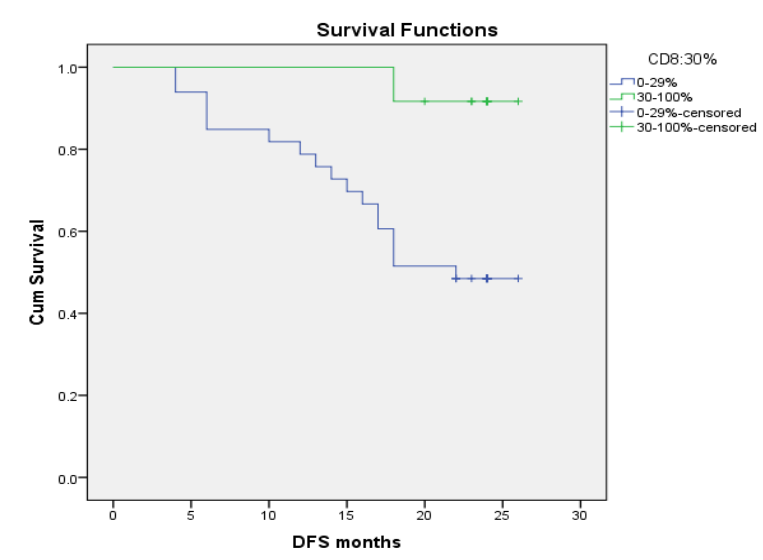

Figure (1): DFS curve according to high and low CD8.

\section{DISCUSSION}

Tumor infiltrating lymphocytes (TILs) are one of the immunological parameters that have been identified as predictors of response to neoadjuvant chemotherapy in breast cancer ${ }^{(9)}$. The contribution of the different TIL subpopulations to the clinical and biological characteristics of $\mathrm{BC}$ remains unclear, particularly in terms of prediction of chemotherapy efficacy. The results of the present study revealed that the high CD8 TIL level may be predictive of small tumor residual and prognostic of better DFS but we didn't find correlation between CD8 and pCR or OS in this patient population. Comparable to our results $\mathbf{L i e u}$ et al. ${ }^{(10)}$, assessed the association of CD8+ TILs with patient survival in different breast cancer intrinsic subtypes and found that breast cancer specific survival is higher in basal like subtypes who are positive CD8 (mean survival time of 14.5 vs versus 11.0 years, $\boldsymbol{P}<\mathbf{0 . 0 0 1}$ ). But $\mathrm{Al}$ saleh et al (11), assessed CD8 in 31 patients with luminal B/HER 2 negative locally advanced breast cancer received neoadjuvant chemotherapy and found that a total of $9 / 16$ patients $(56 \%)$ with high intratumoral CD8 TIL expression achieved pCR, in contrast with 2 out of 15 patients (13.3\%) with low expression $(\boldsymbol{P}=\mathbf{0 . 0 1 6})$. High expression of intratumoral CD8 TIL was significantly associated with OS $(\boldsymbol{P}=\mathbf{0 . 0 2 3})$. This result was quite different from our results. A multicentric neoadjuvant pilot study carried out by Nabholtz et al. (12), investigated the value of CD8 expression as a predictor of $\mathrm{pCR}$ in a series of 60 patients with operable stage II-III triple-negative BC (TNBC), treated with anthracycline-taxane-based chemotherapy plus the anti-HER 1 monoclonal antibody panitumumab. It was reported that high CD8+ TILs counts $(\geq 118)$ predicted an $84 \%$ probability of $\mathrm{pCR}$, as opposed to low counts $(<118)$ yielding a $10 \%$ probability. From all these trial we can conclude that CD8 TIL may be of prognostic and predictive value in breast cancer patients. Additional studies have to be done to identify the group of patients that may benefit from CD8 assessment.

\section{CONCLUSION}

This study confirmed that the CD8 TIL is an important prognostic and predictive factor in breast cancer.

\section{CONFLICTS OF INTEREST}

There are no conflicts of interest.

\section{REFERENCES}

1- Hiatt $R$ and Brody JG (2018): Environmental Determinants of breast cancer. Annu. Rev. Public Health, 39:113-33.

2- Azim HA and Ibrahim AS (2014): Breast cancer in Egypt, china and Chinese: statistics and beyond. J Thorac Dis., 6(7): 864-866.

3- Sun SY, Zhao Z, Yang NZ et al. (2017): Risk Factors and Preventions of Breast Cancer. Int J Biol Sci., 13: 7-13. 
4- Stanton SE and Disis ML (2016): Clinical significance of tumor-infiltrating lymphocytes in breast cancer. Journal for ImmunoTherapy of Cancer, 4:59-63.

5- Dunn GP, Old LJ and Schreiber RD (2004): The three Es of cancer immunoediting. Annu Rev Immunol., 22: 329-360.

6- Ahn SG, Jeong J, Hong S et al. (2015): Current issues and clinical evidence in tumorinfiltrating lymphocytes in breast cancer. J Pathol Transl Med., 49(5):355-363.

7- Melichar B, Študentova $H$, Kalábová $H$ et al. (2014): Predictive and prognostic significance of tumor-infiltrating lymphocytes in patients with breast cancer treated with neoadjuvant systemic therapy. Anticancer Res., 34(3):1115-25.

8- Mahmoud S (2012): CD8 (+) T lymphocytes infiltrating breast cancer: a promising new prognostic marker? Onco Immunol., 1(3):364-5.

9- Savas P, Salgado R, Denkert C, Sotiriou C, Darcy PK, Smyth MJ, Loi S (2016): Clinical relevance of host immunity in breast cancer: from TILs to the clinic. Nature reviews Clinical Oncology, 13(4):228-233.
10- Liu S, Lachapelle J, Leung S et al. (2012): CD8+ lymphocyte infiltration is an independent favorable prognostic indicator in basal-like breast cancer. Breast Cancer Research, 14:R48.

11- Al-saleh K, Abd elaziz N, Ali A et al. (2017): Predictive and prognostic significance of CD8+ tumor infiltrating lymphocytes in patients with luminal B/HER 2 negative breast cancer treated with neoadjuvant chemotherapy. Oncology Letters, 14(1):337-44.

12- Nabholtz JM, Abrial C, Mouret-Reynier MA et al. (2014): Multicentric neoadjuvant phase II study of panitumumab combined with an anthracycline/taxane based chemotherapy in operable triple negative breast cancer: Identification of biologically-defined signatures predicting treat-ment impact. Ann Oncol., 25: 1570-1577. 